\title{
The Transmission of Foreign Interest Rate Shocks to a Small-Open Economy: The Role of External Debt and Financial Integration
}

\author{
Ufuk Devrim Demirel*
}

October, 2008

\begin{abstract}
This paper investigates the implications of external indebtedness and international financial integration on the effects of foreign interest rate shocks in a small-open economy. The theoretical component of the analysis develops a business cycle model that can successfully match the impulse responses of the Turkish economy to U.S. interest rate shocks. It is found in the context of this model that the relationship between financial integration and macroeconomic volatility due to foreign interest rate shocks depends on the level of outstanding external debt. Financial integration mitigates the economy's responses to foreign rate shocks for higher levels of external debt. It magnifies the economy's responses for lower levels of external debt. The model is estimated on quarterly Turkish data. The estimated version reveals that the Turkish Economy's responses to U.S. interest rate shocks would be significantly less pronounced for lower levels of external debt.
\end{abstract}

JEL classification: E30; F36; F41

Keywords: Financial Integration; External Debt; Foreign Shock Transmission; Turkish Economy

\footnotetext{
${ }^{*}$ University of Colorado at Boulder, Department of Economics, 256 UCB, Boulder, CO, 80309, USA, tel: (303) 492 2585, email:demirel@colorado.edu. I would like to thank Martin Boileau, Wolfgang Keller, Martin Uribe and seminar participants at the Central Bank of the Republic of Turkey for helpful comments.
} 


\section{Introduction}

Many developing economies have liberalized their financial markets during the last quarter of the $20^{\text {th }}$ century. The resulting increase in the level of integration with global financial markets has introduced foreign interest rates as important determinants of domestic macroeconomic activity in these economies. This paper presents a theoretical and empirical investigation into the channels through which foreign interest rate shocks influence domestic variables in developing economies. In particular, I address the following questions: What is the role played by external debt in the transmission of foreign interest rate shocks? Does enhanced integration with international capital markets amplify the domestic effects of foreign interest rate fluctuations?

In the theoretical part, I develop a structural model to investigate the implications of external indebtedness and integration with global financial markets on the transmission and prapagation of foreign rate shocks. In the empirical part, I estimate the model on Turkish quarterly data. Turkey underwent radical transformations during the last two decades of the the $20^{\text {th }}$ century. Gradual liberalizations of the trade and capital accounts, initiated in early 1980's, characterized the transformation from an inward-looking import-substitution economy toward a textbook small-open economy. Due to capital market liberalization, which was diligently pursued as a central component of the reform agenda, U.S. interest rates emerged as significant determinants of Turkish business fluctuations. The empirical part quantifies the effects of U.S. interest rate shocks on the Turkish economy and estimates the theoretical model to assess the roles of external indebtedness and the degree of financial integration in shock transmission.

There is a large body of empirical literature investigating the effects of foreign shocks in smallopen economies (see, e.g., Mackowiak (2007), Uribe and Yue (2006), Giovanni and Shambaugh (2006), Canova (2005), Kim (2001), Blankenau et al. (2001)). Although many economists seem to agree on the importance of foreign interest rates' role in domestic economic activity, transmission channels remain controversial. Uribe and Yue (2006) find that, in a sample of Latin American countries, foreign rate shocks impact economic activity mainly through the interest rate spreads that these countries face in international financial markets. Canova (2005), on the other hand, shows that the reaction of Latin American economies to U.S. interest rate shocks is mainly driven by the response of domestic nominal interest rates. Mackowiak (2007) presents further evidence in support of this view by showing that, in a sample of developing economies, interest rate responses to U.S. monetary policy shocks are strong and lead output responses. I corroborate this finding using Turkish data. Much in the spirit of the previous literature, I estimate a VAR model which includes U.S. Treasury bill rates and a mix of real and nominal domestic variables. In the previous empirical studies, however, the sample periods for which these VAR models are estimated often overlaps with transition periods during which the studied economies experience regime switches and implement structural reforms. This puts into question the structural stability of the estimated VAR's. To address this issue, I start the empirical analysis with a detailed stability assessment of the VAR model. I find strong evidence 
in support of parameter instability and estimate a structural break date. Then I reestimate the original VAR for the sub-samples separated by the break date. I find that domestic variables start responding strongly and significantly to U.S. interest rate shocks in the post-break period. In addition to inflation, U.S. rate hikes lead to a contraction in domestic output and investment as well as a real depreciation of the domestic currency. In line with the evidence presented in Canova (2005) and Mackowiak (2007), the domestic nominal rate is found to respond quickly, peaking earlier than the other domestic variables.

To investigate the underlying transmission structure, I next lay out a detailed theoretical framework. The model is of a small-open economy with sectors for final and intermediate products. To effectively address the role of domestic interest rates and monetary policy in foreign shock transmission, I assume costly price adjustment in the final goods sector. In the intermediate goods sector, manufacturers face capital adjustment costs and a working capital requirement. Household preferences are characterized by habit formation and they face portfolio adjustment costs in international financial markets. The degree of financial integration is indexed by the size of portfolio adjustment costs. Monetary policy in the model is formulated as a Taylor-type interest rate rule which admits feedback from contemporaneous inflation and nominal exchange rate depreciation. In the empirical part, some of the model parameters are calibrated to match certain key figures of the Turkish economy, namely average external-debt/GDP, export/GDP and investment/GDP ratios. The remaining parameters are estimated so as to minimize the distance between the model-based impulse responses and the VAR-based impulse responses. The model, with the estimated parameter values, is quite successful in replicating the VAR-based impulse responses in terms of magnitude, persistence as well as non-monotonicity. The model cannot be rejected at conventional significance levels by a standard model specification test (Hansen's J-test).

The theoretical analysis contributes to the literature that studies the impact of financial openness on macroeconomic volatility. Previously, Baxter and Crucini (1995) and Heathcote and Perri (2002) found that consumption volatility is negatively linked to the level of financial integration. Sutherland (1996) and Buch et al. (2005), on the other hand, argued that the relationship between financial openness and macroeconomic volatility depends on the type of shock. My analysis extends this line of research by exploring the role of foreign interest rate shocks. The main finding is that, under incomplete asset markets, the relationship between financial integration and macroeconomic volatility due to foreign interest rate shocks depends on the level of external debt. For higher levels of external debt, financial integration alleviates the economy's responses to foreign rate shocks. It tends to amplify the responses for lower levels of external debt. This feature is due to the interplay of different transmission mechanisms. The model spells out three major transmission channels. As long as the small-open economy is a net debtor, a positive foreign interest rate shock creates a negative wealth effect, depressing aggregate demand and initiating a real contraction. In addition, the shock leads to a fall in investment goods supply 
due to a portfolio reallocation effect as well as a decline in consumption demand through a standard intertemporal substitution effect. Both of these channels consolidate the contractionary impact of the wealth channel. The outstanding foreign debt directly determines the size of the wealth effect. At the same time, the degree of financial integration interferes with the portfolio reallocation and intertemporal substitution effects as portfolio adjustment costs are reflected in equilibrium intertemporal prices. Under enhanced financial integration, which involves lower portfolio adjustment costs, households are able to smooth consumption more effectively in the face of the negative wealth effect associated with a foreign rate shock. Yet, at the same time, if portfolio adjustment costs are less severe, intertemporal substitution and portfolio reallocation effects become more pronounced and tend to deliver stronger consumption and investment responses. For higher levels of external debt, enhanced financial integration significantly improves consumption smoothing capabilities, which helps to mute the economy's responses to foreign rate shocks. For lower levels of external debt, portfolio reallocation and intertemporal substitution motives dominate. In consequence, increased financial openness magnifies the responses to foreign rate shocks.

The remainder of the paper is organized as follows: Section 2 lays out the empirical approach, presents the structural stability analysis and the estimation of the VAR model. Section 3 outlines the theoretical model constructed to interpret the estimated impulse responses. Section 4 presents the estimation of the theoretical model and discusses the results. Section 5 concludes.

\section{Empirical Approach}

This section empirically investigates the effects of U.S. interest rate shocks on the Turkish economy. I employ a six-variable vector autoregression (VAR) system which includes U.S. Treasury bill rates and five domestic variables; private investment, gross domestic product, real exchange rate, consumer price index (CPI) inflation and nominal interest rates. Even though the implications can be quite sensitive to the specification of the VAR, the considered domestic variables are the most relevant indicators of aggregate economic activity that typically contain the information needed to delineate a general macroeconomic picture. Following Uribe and Yue (2006) and Canova (2005), the stochastic process that governs the evolution of the U.S. interest rate is considered exogenous to domestic variables and, conceivably, any possible feedback from the Turkish economy to the U.S. interest rates is ruled out. This assumption yields the following block-VAR form:

$$
\begin{gathered}
\mathbf{S}_{t}=\mathbf{F S}_{t-1}+\boldsymbol{\Omega}_{t} \\
\mathbf{S}_{t}=\left[\begin{array}{c}
R_{t} \\
\mathbf{D}_{t}
\end{array}\right] \quad \mathbf{F}=\left[\begin{array}{ll}
\rho(L) & \mathbf{0} \\
\mathbf{\Psi}_{21}(L) & \mathbf{\Psi}_{22}(L)
\end{array}\right] \quad \boldsymbol{\Omega}_{t}=\left[\begin{array}{c}
\varepsilon_{t} \\
\mathbf{e}_{t}
\end{array}\right]
\end{gathered}
$$


with $\left(\varepsilon_{t}, \mathbf{e}_{t}\right)^{\prime} \sim N(0, \Sigma)$. The vector $\mathbf{D}_{t}$ contains the domestic variables. Seasonally adjusted quarterly data is used and the dataset runs from 1987:1 to 2007:3. ${ }^{1}$ All domestic variables are defined as percentage deviations from stochastic trends. Employing the methods developed in Baxter and King (1999), detrending is performed using an approximate high-pass filter that isolates the cycles with periodicities less than or equal to 32 quarters. The variable $R_{t}$ denotes the log of the gross return on 3-month U.S. Treasury bills. Bayesian information criterion suggests that the best fit is achieved by a $\operatorname{VAR}(1)$ specification. In $(1), \varepsilon_{t}$ is a serially uncorrelated shock to the U.S. interest rate, which is assumed to follow an $\mathrm{AR}(1)$ process, and $\mathbf{e}_{t}$ is understood as a vector of linear combinations of various structural disturbances and possibly $\varepsilon_{t}$.

Uribe and Yue (2006) and Canova (2005) assume that innovations in the U.S. interest rates impact the domestic variables with a one-period lag. This assumption is justified on the grounds that it typically takes time for financial shocks to influence real economic activity. However, in our VAR specification, the domestic block $\mathbf{D}_{t}$ includes real as well as nominal variables, which can potentially respond to U.S. interest rate innovations contemporaneously. Thus, I do not restrict the covariance matrix $\Sigma$ to be block-diagonal and allow for contemporaneous correlation between $\varepsilon_{t}$ and $\mathbf{e}_{t}$.

As mentioned earlier, the interval for which data is available corresponds to a transition period. Therefore, one can reasonably expect parameter instability. To address this issue, I perform structural stability tests using the Andrews (1993) sup-Wald statistic. The potential structural change in each equation of the domestic block is postulated as a one-time break and the break date is treated as an unknown parameter. I jointly test the stability of all autoregressive parameters for each equation of the domestic block. This entails performing five stability tests by considering the following specification:

$$
\mathbf{D}_{t}=\mathbf{M}_{1} I_{t} \mathbf{S}_{t-1}+\mathbf{M}_{2}\left(1-I_{t}\right) \mathbf{S}_{t-1}+\mathbf{v}_{t}
$$

where

$$
I_{t}=\left\{\begin{array}{c}
0 \text { for } t \leq T \\
1 \text { for } t>T
\end{array}\right.
$$

The null hypothesis is $\mathbf{M}_{1}(i)^{\prime}=\mathbf{M}_{2}(i)^{\prime}$ for all $T$ and $i \in\{1,2,3,4,5\}$, where $T$ is a candidate structural break date and $\mathbf{M}_{j}(i)$ denotes the $i^{\text {th }}$ row vector of the $j^{\text {th }}$ matrix. A rejection of the null implies structural instability for the equation in question and the estimated break date is the one that corresponds to the maximum Wald statistic computed under the restriction $\mathbf{M}_{1}(i)^{\prime}=\mathbf{M}_{2}(i)^{\prime}$ for each alternative break date. That is, the estimated break date $T^{*}$ is the one associated with

\footnotetext{
${ }^{1}$ Source: Website of the Central Bank of the Republic of Turkey (http://www.tcmb.gov.tr). Seasonal adjustment is performed adopting the X-12 ARIMA method. Eurostat's Demetra 2.0 software is used.
} 


$$
\sup W_{n}=\sup _{T_{\min } \leq T \leq T_{\max }} W_{n}(T)
$$

where $W_{n}(T)$ is the Wald statistic computed for a given candidate break date $T$ and $n$ denotes the number of observations. The values $T_{\min }$ and $T_{\max }$ respectively correspond to the earliest and the latest candidate break dates. They are chosen such that $T_{\min }=[0.25 \times n]$ and $T_{\max }=[0.75 \times n]$ where [.] denotes the integer part operator. Note that the unknown parameter $T$ appears under the alternative hypothesis but not under the null hypothesis. As discussed in Andrews and Ploberger (1994), this implies non-standard asymptotic distributions for Wald, Likelihood Ratio or Lagrange Multiplier statistics computed under the null. Hansen (1997) develops a method to approximate the quantile function of (3) and compute p-values. Adopting the simulation approach presented in Hansen (1997), I find that the null is easily rejected at $1 \%$ level for four out of five domestic block equations of the VAR. The p-values and corresponding break-date estimates are reported in Table 1 . In addition to the equation-by-equation tests, I also test the stability of individual VAR parameters. This involves performing thirty stability tests. As exhibited in Table 2, the null is rejected at 5\% level for eleven out of thirty VAR parameters. At $10 \%$ level, thirteen out of thirty parameters are found to be unstable. These results are illustrative of prevalent parameter instability.

Next, I assess the implications of the structural change by comparing the pre-break and post-break impulse responses. To this end, the VAR system described in (1) is estimated for the two sub-samples separated by the break-date. However, the estimated break-dates do not suggest a consistent timing for the structural change. That is, breaks are estimated to occur at different points in time for different equations and individual parameters. I choose the first quarter of 1999 as the single break-date since the year 1999 seems to be implicated by the structural stability tests with the highest frequency. Furthermore, this date is meaningful in the historical context as it points to a period in which institutional restructuring was accelerated in the wake of the steep downturn of 1999. The split-sample estimates for the pre-break and post-break parameters are presented in Table 3. Note that there is a striking change especially in the estimates of the U.S. interest rate coefficients. All of the dollar-rate coefficients change signs in the post-break period and significantly so for investment and the nominal interest rate.

Figure 1 exhibits the impulse responses of the domestic variables before and after the structural break to an orthogonalized one-standard-deviation positive shock to the U.S. Treasury bill rate. It is observed that the domestic variables do not notably respond to the dollar-rate shock before the break. However, after the break, private investment and GDP exhibit strong negative hump-shaped impulse responses. CPI inflation, real exchange rate and the nominal interest rate, on the other hand, respond positively. In addition to a sizable contractionary impact, dollarrate shocks seem to exert inflationary pressures in the post-break period. Figure 2 presents the post-break responses within their $90 \%$ confidence intervals. The solid lines are the estimated responses and the dashed lines depict the error bands. Note that the responses in the post-break 
period are quite significant especially in the fourth, fifth and sixth quarters following the shock. In justification of our previous remark, foreign interest rate shocks appear to have assumed a significant role in domestic fluctuations through channels that ostensibly became operational following the structural change.

The finding that foreign interest rates have emerged as significant determinants of the domestic variables is probably anything but surprising for an economy taking major steps towards full integration with international capital markets. However, the critical question stands still: What is the exact mechanism through which U.S. interest rate shocks exert their influence? To propose an answer to this question, I next lay out a full-fledged structural model that bears the characteristics of a small-open economy and is capable of replicating the observed responses of the domestic variables to foreign interest rate shocks.

\section{Theoretical Model}

The model is of a small-open economy populated by four types of agents: Households, manufacturers, retailers and a government.

\subsection{Households}

Households are identical and infinitely lived. They maximize the expected value of a discounted sum of utilities which depend on consumption and labor. More specifically, the representative household maximizes

$$
E_{s}\left\{\sum_{t=s}^{\infty} \beta^{t-s} U\left(C_{t}-\eta C_{t-1}, L_{t}\right)\right\}
$$

where $\beta \in(0,1)$ denotes the subjective discount factor. The variable $C_{t}$ denotes the composite consumption good and $L_{t}$ stands for labor supply. It is assumed that household utility from consumption exhibits habit persistence. The degree of habit persistence is measured by the parameter $\eta$. Habit formation will later prove useful in explaining the hump-shaped impulse responses which, in the previous section, are observed to characterize the economy's responses. The utility function is parametrized as

$$
U\left(C_{t}-\eta C_{t-1}, L_{t}\right)=\frac{\left(C_{t}-\eta C_{t-1}+Z\right)^{1-\kappa}}{1-\kappa}-\frac{L_{t}^{1+\psi}}{1+\psi}
$$

where $\kappa, \psi, Z>0$.

Households accumulate capital, provide manufacturers with capital and labor services and have access to international and domestic bond markets. Households also face a nominal lumpsum tax/transfer scheme denoted by $T_{t}$. Let $\varepsilon_{t}$ denote the nominal exchange rate and $P_{t}$ denote the price level for the composite consumption bundle. Then the household budget constraint 
can be formulated as

$$
\begin{aligned}
& P_{t} C_{t}+P_{t} I_{t}+P_{t} \Phi_{K}\left(I_{t}, K_{t} ; \delta\right)+\varepsilon_{t}\left(F_{t}+\Phi_{F}\left(F_{t} ; F\right)\right)+B_{t} \\
\leq & W_{t} L_{t}+Q_{t} K_{t}+\varepsilon_{t} R_{t-1}^{*} F_{t-1}+R_{t-1} B_{t-1}-T_{t}+\Gamma_{r, t}+\int_{i} \Gamma(i)_{m, t} d i .
\end{aligned}
$$

The evolution of the aggregate capital stock is governed by the rule

$$
K_{t+1}=(1-\delta) K_{t}+I_{t}
$$

Capital depreciates at a constant rate $\delta \in[0,1]$. The variables $I_{t}, K_{t}, B_{t}$ and $F_{t}$ respectively denote gross investment, capital, domestic and foreign net bond positions. The variable $Q_{t}$ stands for the nominal capital rental rate and $W_{t}$ denotes the nominal wage rate. The foreign and domestic gross nominal interest rates are respectively denoted by $R_{t}^{*}$ and $R_{t}$. To remain consistent with the empirical VAR model, it is assumed that $R_{t}^{*}$ follows an $\mathrm{AR}(1)$ process:

$$
\ln R_{t+1}^{*}=(1-\rho) \ln R^{*}+\rho \ln R_{t}^{*}+\varepsilon_{R^{*}, t}
$$

with $\rho \in(0,1)$ and $\varepsilon_{R^{*}, t} \sim N\left(0, \sigma_{\varepsilon}^{2}\right)$, where $R^{*}>0$ denotes the non-stochastic steady-state value for $R_{t}^{*}$. The variables $\Gamma_{m, t}$ and $\Gamma(i)_{r, t}$ stand for manufacturer and retailer dividends.

It is assumed that foreign asset adjustment is costly. The function $\Phi\left(F_{t} ; F\right)$ gives the portfolio adjustment costs in foreign currency. As in Uribe and Yue (2006), the following functional form is chosen:

$$
\Phi_{F}\left(F_{t} ; F\right)=\frac{\omega}{2}\left(F_{t}-F\right)^{2}
$$

The variable $F$ denotes the steady-state level of net foreign assets. Portfolio adjustment costs are commonly employed theoretical devices to induce stationarity in small-open economy models. ${ }^{2}$ In addition to this function, portfolio adjustment costs here determine the extent to which the economy is integrated with international capital markets. The economy is considered financially isolated from the rest of the world as $\omega \rightarrow \infty$ and moves toward full integration as $\omega \rightarrow 0$.

Households are also subject to capital adjustment costs given by the function $\Phi_{K}\left(I_{t}, K_{t} ; \delta\right)$. As will be seen in the following section, capital adjustment costs play a crucial role by enabling the model to produce sensible impulse responses for investment. As it is typically costlier to absorb new capacity at a faster rate, the capital adjustment cost function is assumed to have the following convex form:

$$
\Phi_{K}\left(I_{t}, K_{t} ; \delta\right)=\frac{\phi}{2}\left(\frac{I_{t}}{K_{t}}-\delta\right)^{2} I_{t}
$$

\footnotetext{
${ }^{2}$ See Schmitt-Grohe and Uribe (2003) for a discussion of several alternative specifications that can be used to induce stationarity in a small-open economy model.
} 
Note that this functional form implies zero adjustment costs in the steady-state. In addition to (5) and (6), households also face the following borrowing constraints which rule out Ponzi schemes:

$$
\lim _{k \rightarrow \infty} E_{s}\left(\prod_{t=0}^{k} R_{s+t}^{*}\right)^{-1} F_{s+k+1} \geq 0 \lim _{k \rightarrow \infty} E_{s}\left(\prod_{t=0}^{k} R_{s+t}\right)^{-1} B_{s+k+1} \geq 0
$$

The consumption bundle $C_{t}$ is specified as a Cobb-Douglas aggregate of a domestic component, $C_{H, t}$, and a foreign component, $C_{F, t}$. That is,

$$
C_{t}=\frac{\left(C_{F, t}\right)^{\alpha}\left(C_{H, t}\right)^{1-\alpha}}{\alpha^{\alpha}(1-\alpha)^{1-\alpha}}
$$

where $\alpha \in(0,1)$ denotes the share of the foreign component in the composite consumption good. Furthermore, the domestic and foreign components are specified as CES aggregates of differentiated products indexed by $i \in[0,1]$. More specifically,

$$
C_{H, t}=\left(\int_{0}^{1}\left(C(i)_{H, t}\right)^{1-\frac{1}{\sigma}} d i\right)^{\frac{\sigma}{\sigma-1}} \text { and } C_{F, t}=\left(\int_{0}^{1}\left(C(i)_{F, t}\right)^{1-\frac{1}{\sigma}} d i\right)^{\frac{\sigma}{\sigma-1}}
$$

where $\sigma>1$ measures the elasticity of substitution between differentiated products. Then, CPI is given by

$$
P_{t}=P_{F, t}^{\alpha} P_{H, t}^{1-\alpha}
$$

Let $P(i)_{j, t}$ for $j \in\{F, H\}$ denote the price level for the $i^{t h}$ differentiated domestic or foreign product. The home-currency price indices for the domestic and foreign bundles are then found as

$$
P_{H, t}=\left(\int_{0}^{1}\left(P(i)_{H, t}\right)^{1-\sigma} d i\right)^{\frac{1}{\sigma-1}} \quad \text { and } \quad P_{F, t}=\left(\int_{0}^{1}\left(P(i)_{F, t}\right)^{1-\sigma} d i\right)^{\frac{1}{\sigma-1}} .
$$

Note that $P_{t}, P_{H, t}$ and $P_{F, t}$ give the minimum expenditures needed to assemble one unit of composite, domestic and foreign consumption bundles. It is assumed that the purchasing-powerparity holds so that $P(i)_{F, t}=\varepsilon_{t} P(i)_{F, t}^{*}$ for all $i \in[0,1]$ where $P(i)_{F, t}^{*}$ denotes the foreign-currency price of the $i^{t h}$ differentiated foreign good. It is also assumed that $P(i)_{F, t}^{*}=P_{F, t}^{*}=1$ for all $i$ $\in[0,1]$ and $t$ so that $P_{F, t}=\varepsilon_{t}$.

The optimal allocation of demand across differentiated final products requires

$$
C(i)_{j, t}=\left(\frac{P(i)_{j, t}}{P_{j, t}}\right)^{-\sigma} C_{j, t}
$$

for $j \in\{F, H\}$. Similarly, the allocation of demand across the domestic and foreign consumption 
bundles is governed by the rules

$$
C_{F, t}=\alpha\left(\frac{P_{F, t}}{P_{t}}\right)^{-1} C_{t} \quad \text { and } \quad C_{H, t}=(1-\alpha)\left(\frac{P_{H, t}}{P_{t}}\right)^{-1} C_{t} .
$$

The household problem consists of choosing $\left\{C_{t}, L_{t}, I_{t}, B_{t}, F_{t}\right\}_{t=s}^{\infty}$ to maximize (4) subject to (5), (6) and (8) given the initial asset values, $K_{s}, F_{s-1}$ and $B_{s-1}$. The first-order optimality conditions associated with the household problem are

$$
\begin{aligned}
U_{C, t}\left[1+\omega\left(F_{t}-F\right)\right] & =\beta E_{t}\left\{R_{t}^{*}\left(\frac{S_{t+1}}{S_{t}}\right)^{1-\alpha} U_{C, t+1}\right\} \\
U_{C, t} & =\beta E_{t}\left\{R_{t}\left(\frac{P_{t}}{P_{t+1}}\right) U_{C, t+1}\right\} \\
U_{C, t} Z_{2, t} & =\beta E_{t}\left\{\left[Z_{1, t+1}+(1-\delta) Z_{2, t+1}\right] U_{C, t+1}\right\} \\
-\frac{U_{L, t}}{U_{C, t}} & =\frac{W_{t}}{P_{t}}
\end{aligned}
$$

where $U_{C, t}=\partial U_{t} / \partial C_{t}$,

$$
\begin{aligned}
& Z_{1, t}=\frac{Q_{t}}{P_{t}}+\phi\left(\frac{I_{t}}{K_{t}}-\delta\right)\left(\frac{I_{t}}{K_{t}}\right)^{2} \\
& Z_{2, t}=1+\frac{\phi}{2}\left(\frac{I_{t}}{K_{t}}-\delta\right)^{2}+\phi\left(\frac{I_{t}}{K_{t}}-\delta\right) \frac{I_{t}}{K_{t}}
\end{aligned}
$$

and $S_{t}=\varepsilon_{t} / P_{H, t}$. Equations (11), (12) and (13) are the familiar intertemporal substitution equations associated with the optimal foreign bond, domestic bond and investment decisions. Equation (14) is the standard labor supply relation.

\subsection{Manufacturers}

The economy is also inhabited by a large number of identical manufacturers. Manufacturing firms hire labor and capital from competitive factor markets and produce homogenous intermediate products. Manufacturing firms belong to households and their profits are transferred to the household budget in the form of dividend payments. They use a standard Cobb-Douglas production technology given by

$$
Y_{M, t}=N_{t}^{\gamma}\left(K_{t}^{m}\right)^{1-\gamma}
$$

with $\gamma \in[0,1]$, where $K_{t}^{m}$ and $N_{t}$ denote, respectively, the amounts of capital and labor hired and $Y_{M, t}$ denotes the supply of intermediate manufactured products. Along the lines of Uribe and Yue (2006) and Neumeyer and Perri (2005), it is assumed that manufacturing firms must pay for a certain fraction of their operational costs using liquid, non-interest-bearing assets. This specification is equivalent to a working capital requirement. Let $M_{t}$ denote the amount of 
working capital needed by a typical manufacturing firm. Then the relevant constraint is of the form

$$
M_{t} \geq \mu\left(W_{t} N_{t}+Q_{t} K_{t}^{m}\right)
$$

where the parameter $\mu \geq 0$ determines the fraction of the operational costs required to be paid with liquid assets. Manufacturers' cash flow constraint is then constructed as

$$
W_{t} N_{t}+Q_{t} K_{t}^{m}+A_{t}+M_{t}=X_{t} Y_{M, t}+M_{t-1}+R_{t-1} A_{t-1}-\Gamma_{m, t}
$$

where $A_{t}$ denotes the manufacturer's net nominal interest-bearing assets, $X_{t}$ stands for the price of intermediate manufactured products and $\Gamma_{m, t}$ denotes distributed dividends. Like households, manufacturing firms are subject to a No-Ponzi-Game constraint of the form

$$
\lim _{k \rightarrow \infty} E_{s}\left(\prod_{t=0}^{k} R_{s+t}\right)^{-1} A_{s+k+1} \geq 0 .
$$

Manufacturers solve the following problem to maximize the dividend flow to households taking as given the prices $W_{t}, Q_{t}, R_{t}, X_{t}$ and initial values $A_{s-1}$ and $M_{s-1}$.

$$
\max _{\left\{K_{t}, L_{t}, M_{t}, A_{t}\right\}_{t=s}^{\infty}} E_{s}\left\{\sum_{t=s}^{\infty} \Lambda_{s, t} \Gamma_{m, t}\right\}
$$

subject to (15), (16), (17) and (18). The variable $\Lambda_{s, t}$ denotes the stochastic discount factor with which manufacturers value time- $t$ income. Since manufacturing firms belong to the household, the stochastic discount factor is given by

$$
\Lambda_{s, t}=\beta^{t-s} \frac{U_{C, t}}{U_{C, s}} \frac{P_{s}}{P_{t}}
$$

That is, future random income is discounted on the basis of households' subjective discount factor $\beta$ and marginal utility of income $U_{C, t} / P_{t}$. The first-order-conditions for this problem yield (12) and

$$
\begin{aligned}
X_{t} M P K_{t} & =Q_{t}\left(1+\mu \frac{R_{t}-1}{R_{t}}\right) \\
X_{t} M P L_{t} & =W_{t}\left(1+\mu \frac{R_{t}-1}{R_{t}}\right)
\end{aligned}
$$

where $M P K_{t}$ denotes marginal product of capital and $M P L_{t}$ stands for marginal product of labor. The constraint (16) always holds with equality in an equilibrium with positive nominal interest rates. In addition, the No-Ponzi-Game constraint must also hold with equality. It is observed that the working capital constraint introduces the nominal interest rate to the factor demand equations (20) and (21) in the form of a wedge driven between marginal factor returns 
and costs. The wedge widens as the non-interest-bearing assets that firms are required to keep in the form of working capital increases in proportion to the operational costs.

\subsection{Retailers}

Final goods are produced by a continuum of monopolistically competitive retailer firms indexed by $i \in[0,1]$. These firms buy intermediate inputs from manufacturers and transform them into differentiated final products using a constant-returns-to-scale technology given by

$$
Y(i)_{H, t}=\bar{A}_{r} Y(i)_{m, t}
$$

where $Y(i)_{H, t}$ and $Y(i)_{m, t}$ respectively denote the supply of final goods and the demand for intermediate goods by the $i^{\text {th }}$ domestic retailer firm and $\bar{A}_{r}>0$ is a productivity parameter. Retailer profits are also transferred to households in the form of dividend payments. Each firm faces a downward sloping demand curve implied by (10) for its differentiated final product. In the spirit of Rotemberg (1982), it is assumed that retailers face quadratic price adjustment costs. This assumption leads to gradual domestic price adjustment in response to a shock to marginal cost or demand.

The profit for the retailer $i$ at time $t$ is given by

$$
\Gamma(i)_{r, t}=P(i)_{H, t} Y(i)_{H, t}-X_{t} Y(i)_{m, t}-P_{H, t} \frac{\theta}{2}\left(\frac{P(i)_{H, t}}{P(i)_{H, t-1}}-\pi_{s s}\right)^{2}
$$

where the last term denotes the price adjustment cost incurred by firm $i$ and $\pi_{s s}$ stands for the steady-state gross inflation rate. Retailers seek to maximize the dividend payments to households. Each monopolistically competitive retailer sets the price level for its differentiated product taking as given the intermediate goods price $X_{t}$ to solve

$$
\max _{\left\{P(i)_{H, t}\right\}_{t=s}^{\infty}} E_{s}\left\{\sum_{t=s}^{\infty} \Lambda_{s, t} \Gamma(i)_{r, t}\right\}
$$

subject to (22), (23) and the demand equation implied by (10). As retailer firms belong to households, they also value future random income with the stochastic discount factor defined in (19). At a symmetric equilibrium, retailer maximization yields

$$
\theta \widetilde{\pi}_{H, t}-\sigma Y_{H, t}\left(\frac{X_{t}}{P_{H, t}}-\frac{\sigma-1}{\sigma}\right)=\beta \theta E_{t}\left\{\frac{U_{C, t+1}}{U_{C, t}}\left(\frac{S_{t}}{S_{t+1}}\right)^{\alpha} \widetilde{\pi}_{H, t+1}\right\}
$$

where $\tilde{\pi}_{H, t}=\frac{P_{H, t}}{P_{H, t-1}}\left(\frac{P_{H, t}}{P_{H, t-1}}-\pi_{s s}\right)$. Note that the nominal marginal cost for retailers is given by the price of intermediate goods $X_{t}$. It follows from (24) that in the absence of price adjustment costs (when $\theta=0$ ), retail prices are set as mark-ups over marginal costs, that is $P_{H, t}=\frac{\sigma}{\sigma-1} X_{t}$. 


\subsection{Government}

The government conducts monetary policy by setting the gross return on the one-period domestic bond. This specification is justified on the grounds that the short-term interbank rate is officially declared by the Turkish Central Bank as the primary policy instrument. The monetary authority in the model conducts open market operations in the domestic bond market to implement its desired interest rate policy. Resulting central bank profits/losses are transferred to the consolidated government budget. I follow Devereux et al. (2006) in assuming that the monetary authority formulates the desired path for the gross nominal rate as a Taylor-type feedback rule of the form

$$
R_{t}=R\left(\frac{P_{H, t}}{P_{H, t-1}}\right)^{\lambda_{\pi}}\left(\frac{\varepsilon_{t}}{\varepsilon_{t-1}}\right)^{\lambda_{\varepsilon}}
$$

where $R>0$ denotes a long-term nominal rate target. The feedback rule (25) completely characterizes the monetary policy in the model. The parameter $\lambda_{\pi}>0$ governs the response of the

policy instrument to a given deviation of gross domestic inflation from unity, hence, measures the anti-inflationary responsiveness of the monetary authority. The parameter $\lambda_{\varepsilon}>0$ determines, in a similar sense, the degree to which the monetary authority seeks to control exchange rate fluctuations. The feedback rule (25) encompasses a wide range of policy specifications. For instance, a fixed exchange rate regime involves $\lambda_{\varepsilon} \rightarrow \infty$ and $\lambda_{\pi} \rightarrow 0$. Intermediate cases, such as a dirty float, can also be captured by this formulation by assigning appropriate values to the parameters $\lambda_{\pi}$ and $\lambda_{\varepsilon}$. Thus, even though the rule (25) may not reflect the exact official policy procedure, it provides a useful conjecture to interpret the realized monetary practice within the taxonomy of benchmark policies.

A government budget constraint for this economy can be constructed as

$$
B_{t}^{G}-R_{t-1} B_{t-1}^{G}=T_{t}
$$

where $B_{t}^{G}$ denotes the net domestic bond position of the central bank. Equation (26) simply states that central bank losses (profits) are financed by (transferred to) households through the lump-sum tax/transfer scheme.

\subsection{Equilibrium}

Competitive equilibrium allocations, in addition to solving the household, manufacturer and retailer problems, must satisfy the following market-clearing conditions: 


$$
\begin{aligned}
Y_{H, t}-\frac{\theta}{2}\left(\frac{P_{H, t}}{P_{H, t-1}}-\pi_{s s}\right)^{2} & =(1-\alpha) S_{t}^{\alpha}\left(C_{t}+I_{t}+\Phi_{K}\left(I_{t}, K_{t} ; \delta\right)\right)+C_{H, t}^{*} \\
B_{t}^{G} & =-B_{t}-A_{t} \\
Y_{M, t} & =\int_{i} Y(i)_{m, t} d i \\
K_{t} & =K_{t}^{m} \\
L_{t} & =N_{t}
\end{aligned}
$$

Equation (27) is the clearing condition for the final goods market. The first term on the righthand-side of (27) denotes the domestic component of the aggregate demand. The second term on the left-hand-side stands for the price adjustment costs defined in terms of the home product and $C_{H, t}^{*}$ denotes the demand by foreigners for domestically produced goods. Following Gali and Monacelli (1999), it is assumed that the share of imported goods in the rest of the world's consumption bundle is negligibly small, that is $P_{t}^{*}=P_{F, t}^{*}=1$. Therefore ${ }^{3}$

$$
C_{H, t}^{*}=\left(\frac{P_{H, t}}{\varepsilon_{t} P_{F, t}^{*}}\right)^{-\sigma} C_{t}^{*}=S_{t}^{\sigma} C_{t}^{*} .
$$

It is further assumed that the level of consumption demand in the rest of the world $C_{t}^{*}$ is exogenous and constant.

Equation (28) is the bond market clearing condition and (29) is the clearing condition for the intermediate goods market. The term on the right-hand-side of (29) denotes the aggregate demand for intermediate inputs by retailers. Equations (30) and (31) are, respectively, the capital and labor market clearing conditions. An aggregate balance-of-payments constraint can also be constructed by incorporating the manufacturer and retailer cash flow constraints and the government budget constraint into the household budget constraint, which yields

$$
\alpha\left(C_{t}+I_{t}+\Phi_{K}\left(I_{t}, K_{t} ; \delta\right)\right)+S_{t}^{1-\alpha}\left(F_{t}+\Phi_{F}\left(F_{t} ; F\right)-R_{t-1}^{*} F_{t-1}\right)=S_{t}^{-\alpha} C_{H, t}^{*}
$$

Since an exact analytical solution is not feasible, the system of non-linear equations that describe the evolution of the competitive equilibrium allocations is log-linearized around a nonstochastic steady-state. ${ }^{4}$ Employing the methods developed in Sims (1999), the log-linearized system of equations is expressed in the form

$$
\mathbf{W}_{1} \mathbf{Y}_{t+1}=\mathbf{W}_{2} \mathbf{Y}_{t}+\mathbf{W}_{3} \varepsilon_{R^{*}, t+1}+\mathbf{W}_{4}\left(\mathbf{Y}_{t+1}-E_{t} \mathbf{Y}_{t+1}\right)
$$

where the vector $\mathbf{Y}_{t}$ contains the percentage deviations of the endogenous variables from their

\footnotetext{
${ }^{3}$ It is assumed that the domestic economy has the same elasticity of substitution $(\sigma)$ with the rest of the world.

${ }^{4}$ The system of linearized equations is constructed using (7), (11)-(14), (20), (21), (15), (22), (24), (25), (27)-(31) and (32).
} 
non-stochastic steady-state values. The linear system of equations (33) is solved using the eigenvalue-eigenvector decomposition technique. Provided that one exists, the solution is of the form

$$
\mathbf{Y}_{t+1}=\mathbf{J}_{1} \mathbf{Y}_{t}+\mathbf{J}_{2} \varepsilon_{R^{*}, t+1}
$$

The matrix $\mathbf{J}_{1}$ and the vector $\mathbf{J}_{2}$ are functions of the model's structural parameters. The fit of the theoretical model for a given set of parameters is assessed by comparing the impulse responses produced by (34) with those of the empirical VAR model.

\section{Estimation}

This section outlines the estimation methodology and presents the results. In section 2, we obtained a set of empirical estimates for the impulse responses of the domestic variables to a given U.S. interest rate shock for the two sub-samples separated by the estimated structural break date. We observed that the responses in the post-break period are highly pronounced and significant. In order to propose a structure for the transmission of U.S. interest rate shocks, I next interpret the post-break responses within the theoretical framework just described.

\subsection{Methodology}

The estimation strategy is based on minimizing the distance between the impulse responses of the theoretical model obtained by simulating (34) and the impulse responses produced by the estimated VAR in the post-break period. As argued in Boivin and Giannoni (2006), this approach can be viewed as a special case of semi-parametric indirect inference discussed in Dridi and Renault (2001). A number of other studies, namely Uribe and Yue (2006), Christiano et al. (2005) and Cogley and Nason (1995) employ the same methodology in different contexts.

The set of structural parameters, $\boldsymbol{\Theta}$, is partitioned into two subsets: $\boldsymbol{\Theta}_{1}$ and $\boldsymbol{\Theta}_{2}$. In $\boldsymbol{\Theta}_{1}$ lay the parameters $\{\beta, \rho, \delta, \sigma, \gamma, \alpha, \psi, F\}$, which are either already identified by the VAR (parameter $\rho$ ) or are calibrated. The parameter $\beta$ is set so that the steady-state value for the real interest rate the country faces in international capital markets is roughly $10 \%$. This value is given by the summation of an average U.S. Treasury bill rate of $4 \%$ and an average country spread of about $6 \% .^{5}$ The autoregressive parameter $\rho$ is estimated to be around 0.944 . The depreciation rate $\delta$ is set so that, in the steady-state, the investment/output ratio is about 0.20 ; the average figure for the Turkish economy in the sample period. The elasticity of substitution between differentiated products $\sigma$ is set so that the average mark-up is around 20\%. The retail sector productivity parameter $\bar{A}_{r}$ is normalized to unity. Following Uribe and Yue (2006), the share of capital in the production function, $\gamma$, is set to 0.32 and as in Devereux et al. (2006) the labor supply elasticity parameter $\psi$ is set to unity. The foreign debt parameter $F$ is chosen so

\footnotetext{
${ }^{5}$ The country spread is measured by J.P. Morgan's EMBI+ index.
} 
as to ensure that the steady-state dollar-denominated-debt/GDP ratio is around 0.31, which is roughly the average value for the sample period. The foreign goods share parameter, $\alpha$, is set to 0.33 so that the average steady-state import/GDP ratio is around 0.32 ; the average figure for the Turkish economy in the post-break period.

The remaining structural parameters of the model $\Theta_{2}=\left\{\omega, \phi, \theta, \eta, \mu, \lambda_{\pi}, \lambda_{\varepsilon}, Z, \kappa\right\}$ are estimated. Let $\boldsymbol{\Phi}_{v a r}$ and $\boldsymbol{\Phi}_{m}\left(\boldsymbol{\Theta}_{1}, \boldsymbol{\Theta}_{2}\right)$ denote the vectors that collect, respectively, the VAR-based impulse responses and those produced by the theoretical model. I consider the impulse responses for the real exchange rate, investment, real GDP, CPI inflation and the domestic nominal interest rate over the first twelve quarters following the shock to the U.S. interest rate. Thus, both $\boldsymbol{\Phi}_{\text {var }}$ and $\boldsymbol{\Phi}_{m}\left(\boldsymbol{\Theta}_{1}, \boldsymbol{\Theta}_{2}\right)$ are $(60 \times 1)$ vectors. Then the estimation problem is

$$
\min _{\boldsymbol{\Theta}_{2}}\left[\boldsymbol{\Phi}_{v a r}-\boldsymbol{\Phi}_{m}\left(\boldsymbol{\Theta}_{1}, \boldsymbol{\Theta}_{2}\right)\right]^{\prime} \boldsymbol{\Psi}\left[\boldsymbol{\Phi}_{v a r}-\boldsymbol{\Phi}_{m}\left(\boldsymbol{\Theta}_{1}, \boldsymbol{\Theta}_{2}\right)\right]
$$

where $\boldsymbol{\Psi}$ is a $(60 \times 60)$ positive-definite weighting matrix. The estimation is performed using two different weighting matrices. First, I employ a diagonal matrix whose elements are given by the inverse of the corresponding impulse response estimate's variance. This choice is motivated by the fact that some impulse responses are more imprecisely estimated than others. This weighting matrix assigns relatively smaller weights on the impulse responses that are less precisely estimated. Table 4 reports the estimation results and the search regions for each structural parameter. Next, I estimate the model using the efficient weighting matrix given by the inverse variance-covariance matrix of the VAR-based impulse responses. The efficient weighting matrix is used to compute Hansen's J-statistic, which provides us with a model specification test.

For certain regions of the parameter space, the theoretical model produces equilibrium indeterminacy. Typically, indeterminacy arises in the model if the anti-inflationary response parameter of the nominal interest rate rule (25) falls below a threshold level. To avoid such outcomes, the search is confined to the regions in which the theoretical model yields a unique rational expectations equilibrium.

\subsection{Results}

Figure 3 compares the impulse responses of the empirical VAR with those of the theoretical model computed under the estimated parameter values. ${ }^{6}$ The theoretical model is quite successful in replicating both the qualitative and the quantitative features of the estimated VAR responses. All 60 theoretical responses are within the estimated $90 \%$ confidence intervals. In addition to the key features that output and investment contract and CPI inflation, the nominal interest rate and the real exchange rate rise in response to a positive foreign rate shock, the model can capture the persistence and non-monotonicity of the estimated impulse responses quite well.

\footnotetext{
${ }^{6}$ The structural parameters that are used in the simulation of the theoretical impulse responses exhibited in Figure 3 are estimated using the diagonal weighting matrix.
} 
Table 4 reports Hansen's J-statistic and the associated p-value. The value of the J-statistic computed using the efficient weighting matrix is 16.196. Since the impulse response vector has 60 rows and a total of 9 structural parameters are being estimated, the J-statistic is asymptotically $\chi^{2}(51)$. The corresponding p-value for the computed J-statistic is greater than 0.99 . Thus, the J-test does not reject the model even at $1 \%$ level.

To evaluate the implications of the structural parameter estimates, it is crucial to put the values reported in table 4 in context. The portfolio adjustment cost estimate implies that a $10 \%$ increase in outstanding debt from its steady-state value for a year is associated with an output cost of about $0.83 \%$ of the real GDP. This result implies considerably more severe portfolio adjustment costs for the Turkish economy than for a sample of Latin American countries as reported in Uribe and Yue (2006). Capital adjustment costs, on the other hand, appear somewhat less substantial. A $10 \%$ increase in investment form its steady-state value results in a $1.24 \%$ increase in capital stock. In the absence of capital adjustment costs, the same increase in investment results in a $1.3 \%$ increase in capital stock. The estimated value for the price adjustment cost parameter implies that a $5 \%$ deviation of the annualized inflation rate from its steady-state level has a cost of $2.1 \%$ of the real GDP. This result indicates high and significant output costs associated with inflation deviations from the trend rate. In addition, the estimate for the parameter $\eta$ suggests a high degree of habit persistence. The value 0.931 is greater than the value for Latin America estimated in Uribe and Yue (2006). It is close to the value for the U.S. economy in the pre-1980 period as reported in Boivin and Giannoni (2006). Together with the estimated values for $\kappa$ and $Z$, this result for the parameter $\eta$ implies that the intertemporal elasticity of substitution is around $0.26 .^{7}$ The estimate for $\mu$ implies that manufacturers keep a level of non-interest bearing assets equal to 9.7 months of wage payments. Finally, the estimates for the monetary policy parameters $\lambda_{\pi}$ and $\lambda_{\varepsilon}$ indicate a strong anti-inflationary stance for monetary policy in the post-break period. This result is consistent with the inflation targeting regime the Central Bank of Turkey gradually adopted after the 2001 crisis.

\subsection{Interpretation and Counterfactual Analysis}

Encouraged by the model's quantitative success, I next turn to interpret the estimated responses in the light of the outlined theory. In the model, the positive shock to the foreign rate increases the opportunity cost of domestic investment, hits investment goods supply and results in portfolio reallocation. In addition, since the country is a net debtor in the steady-state, the foreign rate shock exerts a negative wealth effect along with a standard intertemporal substitution effect on households. These effects result in an increase in labor supply and a fall in consumption demand, which, coupled with the decline in investment goods supply, induces a substantial real contraction. The hump-shaped output and investment responses are primarily driven by

\footnotetext{
${ }^{7}$ The inverse of the intertemporal elasticity of substitution is given by $-\frac{u_{c c} c}{u_{c}}$, where $c$ denotes the non-stochastic steady-state value of consumption.
} 
habit persistence and also in part by capital adjustment costs. Meanwhile, the positive dollarrate shock leads to a capital outflow as it prompts the domestic agents to accumulate more dollar-denominated assets. Consequently, the domestic currency depreciates, which generates the observed hump-shaped increase in the real exchange rate.

On the nominal side, the responses of the domestic interest rate and CPI inflation are interpreted as follows. The contractionary pressure parallels a gradual decline in the demand for labor and capital services. Upon impact, the lack of demand in the factor markets and the accompanying fall in factor prices place a downward pressure on domestic goods' prices. This pressure, however, is outweighed by the expected increase in factor prices in the subsequent quarters driven mainly by the gradual cut in investment goods supply. In consequence, domestic prices, which are given by present and discounted expected future marginal costs, increase in a non-monotonic fashion (exhibiting a hump-shaped response). Note that foreign goods' prices also rise as a result of the aforementioned exchange rate depreciation which, together with the increase in domestic prices, generates the observed positive response in CPI. Facing inflationary pressures and currency depreciation, the monetary authority raises the domestic nominal interest rate. The nominal rate response bears the same non-monotonic characteristics with CPI inflation and nominal exchange rate depreciation since, in the model, monetary policy is devised as a feedback rule that responds to these two variables. The increase in the nominal interest rate, which was highlighted in the previous empirical studies, is then interpreted in the model as a monetary policy reaction in the face of inflationary pressures and currency depreciation.

To quantify the relative importance of the transmission channels, figure 4 exhibits the counterfactual responses to a one-standard-deviation positive foreign rate shock in two separate versions of the economy where portfolio adjustment costs and external debt are $50 \%$ lower than the estimated (benchmark) version. It is observed in the first column of figure 4 that in the version where external debt is $50 \%$ lower, the responses are significantly muted compared to those produced by the benchmark model. On the other hand, under enhanced financial integration (where portfolio adjustment costs are $50 \%$ lower), the responses are virtually similar to those produced by the benchmark model as exhibited in the second column of figure 4 . Since the outstanding external debt directly determines the size of the wealth effect, this finding strongly suggests that the wealth channel plays the dominant role in shaping the economy's responses to U.S. interest rate shocks. The economy does not necessarily become more susceptible to foreign interest rate fluctuations as it becomes more integrated with international capital markets. However, it does seem to become more insulated from foreign rate shocks with a lower level of external debt.

To interpret this finding, it is essential to understand the interplay of financial integration and external debt in the model. Enhanced financial integration (lower portfolio adjustment costs) offers more favorable terms for consumption smoothing in the face of a negative wealth shock. Since it is less costly to accumulate dollar-denominated debt in an economy with a higher degree 
of financial integration, the response of consumption to an adverse wealth effect created by a positive shock to the dollar-rate tends to be less pronounced. On the other hand, a reduction in portfolio adjustment costs, at the same time, strengthens the intertemporal substitution and portfolio reallocation motives which work in the opposite direction and tend to magnify the responses of investment as well as consumption. That is, in the face of a given increase in the return on foreign bonds, households are tempted to accumulate more dollar-denominated assets if the cost of foreign asset accumulation is lower. Due to the mutually offsetting nature of these tendencies, a change in the degree of financial integration in the model did not make a notable difference in equilibrium responses. Yet, generally speaking, if the wealth effect is large due to a high level of external debt, the consumption smoothing aspect of financial integration becomes dominant, which means that enhanced financial integration mitigates the economy's real responses to foreign interest rate shocks. Alternatively, if the wealth effect is relatively small due to a low level of external debt, the intertemporal substitution and portfolio reallocation motives arise as the dominant aspects. In this case, an increase in the degree of financial integration exacerbates the economy's responses. This finding suggests a critical level of external debt above which enhanced financial integration renders the economy more vulnerable to foreign interest rate shocks.

\section{Conclusion}

Foreign interest rate movements have significant implications on the behavior of domestic macroeconomic fundamentals in developing countries. In these economies, positive foreign rate shocks are typically associated with real contraction, inflation and currency depreciation. This paper seeks to contribute to our understanding of foreign interest rate transmission by theoretically and empirically evaluating the implications of external debt and the level of financial integration.

The theoretical component of the analysis finds that foreign interest rate movements percolate into the domestic economy through wealth, intertemporal substitution and portfolio reallocation channels. The empirical component quantifies the relative contributions of these channels using Turkish data, and concludes that the wealth effect is the dominant driving force behind the observed responses. The theoretical model, under the estimated parameter values, predicts that the economy can be rendered significantly less responsive to foreign rate shocks by reducing the level of dollar-denominated debt which serves to limit the extent of the wealth effect. In contrast, a major adjustment in the level of integration with global capital markets does not change the economy's responses significantly.

A direction for future research is to account for the relationship between domestic macroeconomic fundamentals and the interest rates faced in international financial markets. As argued in Uribe and Yue (2006), country spreads respond systematically to domestic macroeconomic variables and, in a sample of Latin American countries, are shown to exacerbate the effects of 
foreign interest rate shocks. Taking into account the feedback from domestic fundamentals to the interest rate faced in global markets is a reasonable extension yet is subject to limitations on data availability. Another direction is to include more shocks into the analysis. As discussed in Boivin and Giannoni (2006), including different shocks, provided that they can be plausibly identified, yields more efficient parameter estimates.

A common critique of financial integration is that, under incomplete asset markets, it can potentially destabilize a small-open economy by exacerbating the effects of foreign financial shocks. The analysis presented in this paper suggests that the validity of this argument depends on the country's outstanding level of external debt. It is in this sense essential to enhance our understanding of the underlying factors that simultaneously determine external debt and financial integration and their interaction. 


\section{References}

[1] Andrews, D. W. K. (1993). Tests for parameter instability and structural change with unknown change points. Econometrica 61, 821-856.

[2] Andrews, D. W. K., and W. Ploberger (1994). Optimal tests when a nuisance parameter is present only under the alternative. Econometrica 62, 1383-1414.

[3] Baxter, M., and M. J. Crucini (1995). Business cycles and the asset structure of foreign trade. International Economic Review 36, 821-854.

[4] Baxter, M., and R. G. King (1999). Measuring business cycles: Approximate band-pass filters for economic time series. The Review of Economics and Statistics 81, 575-593.

[5] Blankenau, W., M. A. Kose., and K. Yi (2001). Can world real interest rates explain business cycles in a small open economy? Journal of Economic Dynamics and Control 25, 867-889.

[6] Boivin, J., and M. Giannoni (2006). Has monetary policy become more effective? The Review of Economics and Statistics 88, 445-462.

[7] Buch, C. M., J. Dopke, and C. Pierdzioch (2005). Financial openness and business cycle volatility. Journal of International Money and Finance 24, 744-765.

[8] Canova, F. (2005). The transmission of U.S. shocks to Latin America. Journal of Applied Econometrics 20, 229-251.

[9] Christiano, L. J., M. Eichenbaum , and C. L. Evans (2005). Nominal rigidities and the dynamic effects of a shock to monetary policy. Journal of Political Economy 113, 1-45.

[10] Cogley, T., and J. M. Nason (1995). Output dynamics in real-business-cycle models. The American Economic Review 85, 492-511.

[11] Devereux, M. B., P. R. Lane, and J. Xu (2006). Exchange rates and monetary policy in emerging market economies. The Economic Journal 116, 478-506.

[12] Dridi, R., and E. Renault (2001). Semi-parametric indirect inference. Mimeo, Universite de Montreal and CREST-Insee.

[13] Gali, J., and T. Monacelli (1999). Optimal monetary policy and exchange rate volatility in a small open economy. Mimeo.

[14] Giovanni, J., and J. C. Shambaugh (2006). The impact of foreign interest rates on the economy: The role of the exchange rate regime. IMF Working Paper WP 06/37.

[15] Hansen, B. E. (1997). Approximate asymptotic p-values for structural change tests. Journal of Business \& Economic Statistics 15, 60-67. 
[16] Heathcote, J., and F. Perri (2002). Financial autarky and international business cycles. Journal of Monetary Economics 49, 601-627.

[17] Kim, S. (2001). International transmission of U.S. monetary policy shocks: Evidence from VAR's. Journal of Monetary Economics 48, 339-372.

[18] Mackowiak, B. (2007). External shocks, U.S. monetary policy and macroeconomic fluctuations in emerging markets. Journal of Monetary Economics 54, 2512-2520.

[19] Neumeyer, P. A., and F. Perri, (2005). Business cycles in emerging economies: The role of interest rates. Journal of Monetary Economics 52, 345-380.

[20] Rotemberg, J., (1982). Sticky prices in the United States. Journal of Political Economy 90, $1187-1211$.

[21] Schmitt-Grohe, S., and M. Uribe (2003). Closing small open economy models. Journal of International Economics 61, 163-185.

[22] Sims, C. (1999). Solving linear rational expectations models. Mimeo, Princeton University.

[23] Sutherland, A., (1996). Financial market integration and macroeconomic volatility. Scandinavian Journal of Economics 98, 521-539.

[24] Uribe, M., and V. Yue (2006). Country spreads and emerging countries: Who drives whom? Journal of International Economics 69, 6-36. 


\section{Appendix: Tables and Figures}

\begin{tabular}{lccc}
\hline \hline Null Hypothesis & Sup-Wald Statistic & P-value & Break Date \\
\hline $\mathbf{M}_{1}(2)^{\prime}=\mathbf{M}_{2}(2)^{\prime}$ & 21.04 & 0.0239 & $1999: 4$ \\
$\mathbf{M}_{1}(3)^{\prime}=\mathbf{M}_{2}(3)^{\prime}$ & 10.94 & 0.4799 & - \\
$\mathbf{M}_{1}(4)^{\prime}=\mathbf{M}_{2}(4)^{\prime}$ & 27.23 & 0.0023 & $1997: 4$ \\
$\mathbf{M}_{1}(5)^{\prime}=\mathbf{M}_{2}(5)^{\prime}$ & 54.17 & 0.0000 & $1994: 3$ \\
$\mathbf{M}_{1}(6)^{\prime}=\mathbf{M}_{2}(6)^{\prime}$ & 21.17 & 0.0228 & $2000: 1$ \\
\hline \hline \multicolumn{4}{l}{ Note: $M_{i}(k)$ refers to the $k^{t h}$ row vector of the matrix $M_{i}}$. \\
\hline \hline
\end{tabular}

Table 1: Equation-by-equation stability of the VAR

\begin{tabular}{ccccccc}
\hline \hline & \multicolumn{5}{c}{ Regressors } \\
\cline { 2 - 6 } Dep. Variable & Dollar-rate & Real Exch. Rate & Output & Investment & Inflation & Nom. Int. Rate \\
\hline Real Exch. Rate & 0.0300 & 0.0118 & 1.0000 & 0.6109 & 0.0878 & 0.0346 \\
Output & 0.3705 & 0.2617 & 0.6438 & 0.4609 & 0.3640 & 0.4255 \\
Investment & 0.0083 & 0.0649 & 0.6910 & 0.1502 & 0.0132 & 0.2556 \\
Inflation & 0.4206 & 0.0089 & 0.2805 & 0.0228 & 0.0000 & 0.0127 \\
Nom. Int. Rate & 0.0018 & 0.7914 & 0.1501 & 0.1006 & 0.0077 & 0.2813 \\
\hline \hline
\end{tabular}

Note: The reported figures are the p-values for the sup-Wald tests run for individual VAR parameters.

Table 2: Individual parameter stability of the VAR 


\begin{tabular}{|c|c|c|c|c|c|c|}
\hline \multicolumn{7}{|c|}{ Pre-Break Sample } \\
\hline \multirow[b]{2}{*}{ Dep. Variable } & \multicolumn{6}{|c|}{ Regressors } \\
\hline & Dollar-rate & Real Exch. Rate & Output & Investment & Inflation & Nom. Int. Rate \\
\hline Real Exch. Rate & -0.0629 & $0.7445^{* * *}$ & 0.1792 & -0.3949 & -0.0273 & $0.1691^{* * *}$ \\
\hline Output & 0.0405 & -0.0797 & $0.8644^{* * *}$ & -0.1706 & 0.0737 & $-0.3320^{* * *}$ \\
\hline Investment & 0.0122 & 0.0424 & $0.2144^{* * *}$ & 0.2341 & $0.0536^{* * *}$ & $-0.1868^{* * *}$ \\
\hline Inflation & 0.1172 & -0.0309 & 0.2193 & 0.6525 & -0.1912 & $0.8347^{* * *}$ \\
\hline Nom. Int. Rate & -0.1062 & -0.2675 & 0.4184 & -0.1562 & $-0.3052^{* * *}$ & $0.8300^{* * *}$ \\
\hline \multicolumn{7}{|c|}{ "Post-Break Sample } \\
\hline \multirow[b]{2}{*}{ Dep. Variable } & \multicolumn{6}{|c|}{ Regressors } \\
\hline & Dollar-rate & Real Exch. Rate & Output & Investment & Inflation & Nom. Int. Rate \\
\hline Real Exch. Rate & 0.5225 & 0.1770 & -0.0186 & 0.7764 & $0.2741^{*}$ & $0.3525^{* * *}$ \\
\hline Output & -0.3397 & $-0.5422^{*}$ & $0.9270^{* * *}$ & -0.8894 & -0.0978 & $-0.2356^{*}$ \\
\hline Investment & $-0.1988^{* *}$ & $-0.1928^{* * *}$ & $0.1845^{* * *}$ & $-0.5142^{*}$ & $-0.0545^{*}$ & $-0.1438^{* * *}$ \\
\hline Inflation & -0.5111 & $0.8918^{* * *}$ & 0.1224 & -0.0301 & 0.2185 & $0.4986^{* * *}$ \\
\hline Nom. Int. Rate & $1.7778^{* * *}$ & -0.2235 & -0.4020 & $3.9171^{*}$ & $0.5855^{* *}$ & $0.6054^{* * *}$ \\
\hline
\end{tabular}

Table 3: Split-sample VAR estimates

\begin{tabular}{ccc}
\hline \hline Parameter & Estimated Value & Search Range \\
\hline$\omega$ & 322.4 & $(0, \infty)$ \\
$\phi$ & 47.87 & $(0, \infty)$ \\
$\theta$ & 508.8 & $(0, \infty)$ \\
$\eta$ & 0.931 & $(0,0.99]$ \\
$\mu$ & 3.268 & $(0,10]$ \\
$\lambda_{\pi}$ & 2.745 & $(0, \infty)$ \\
$\lambda_{\varepsilon}$ & 1.377 & $(0, \infty)$ \\
$Z$ & 0.338 & $(0, \infty)$ \\
$\kappa$ & 5.534 & $(0,10]$ \\
\hline \hline
\end{tabular}

Hansen's J-statistic: 16.196; P-value > 0.99

Note: The J-statistic is computed using the efficient weighting matrix.

Table 4: Structural Parameter Estimates 

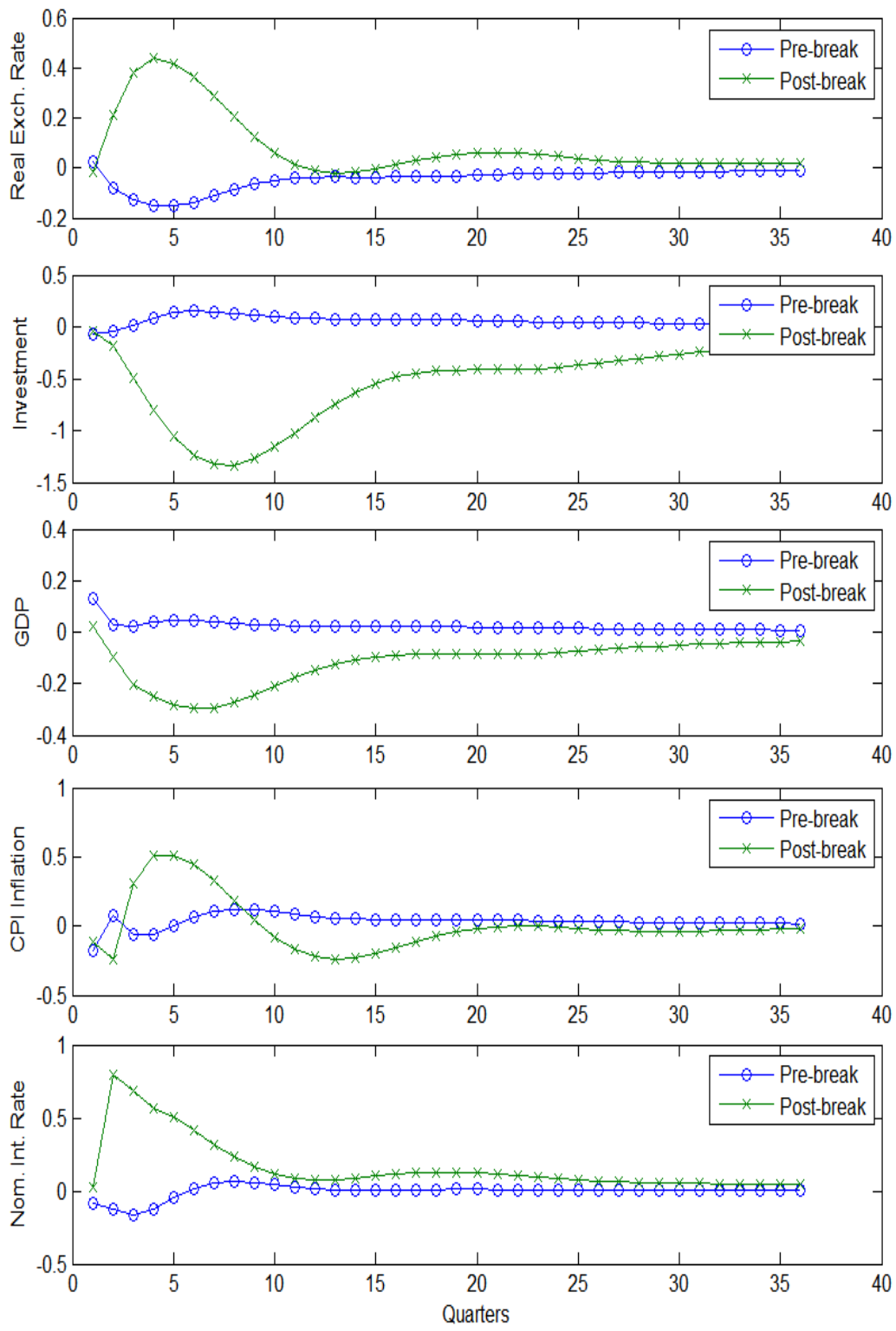

Figure 1: Responses to an orthogonalized one-standard-deviation positive shock to the U.S. Treasury bill rate 

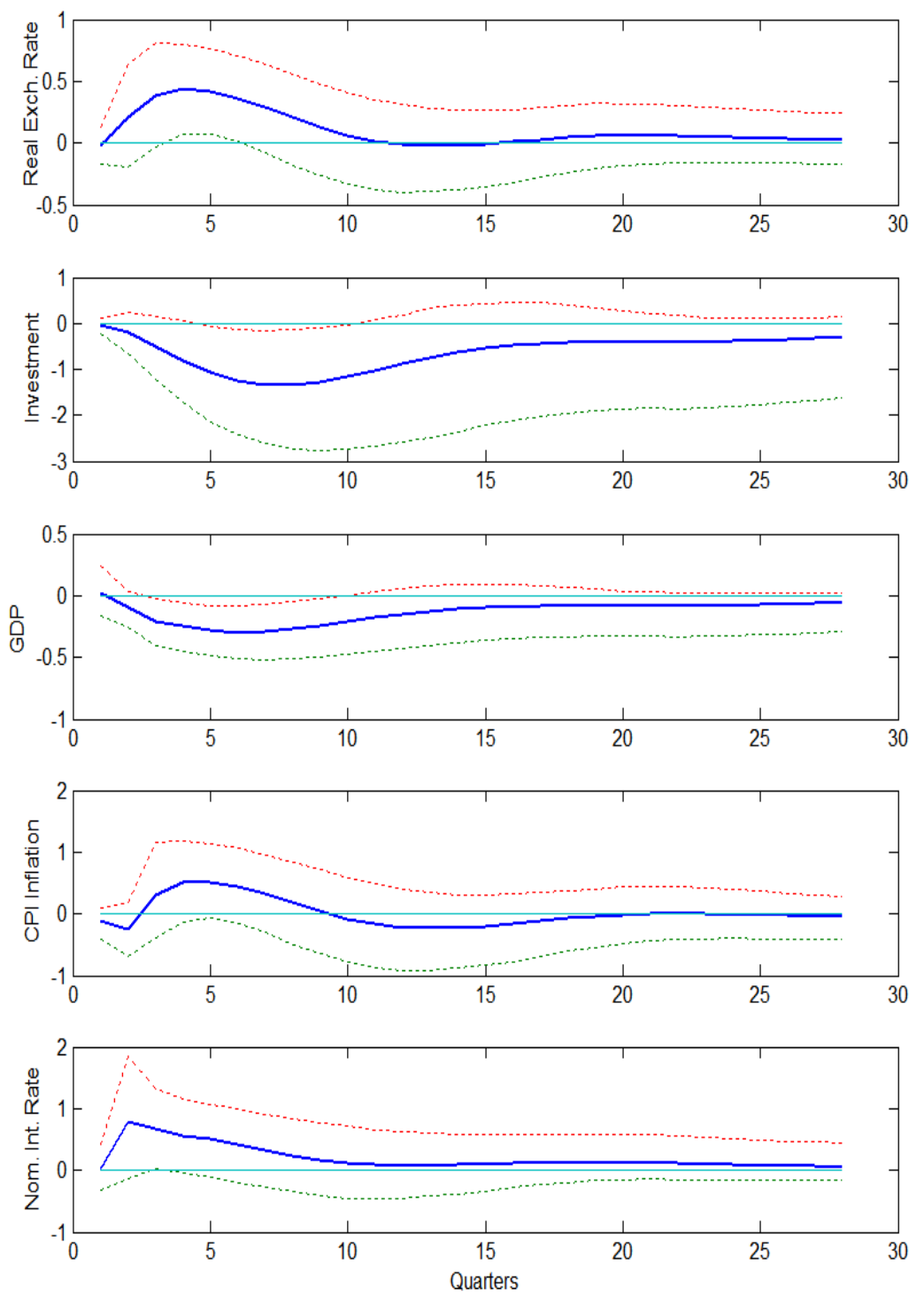

Figure 2: Post-break responses in their 90\% confidence intervals 

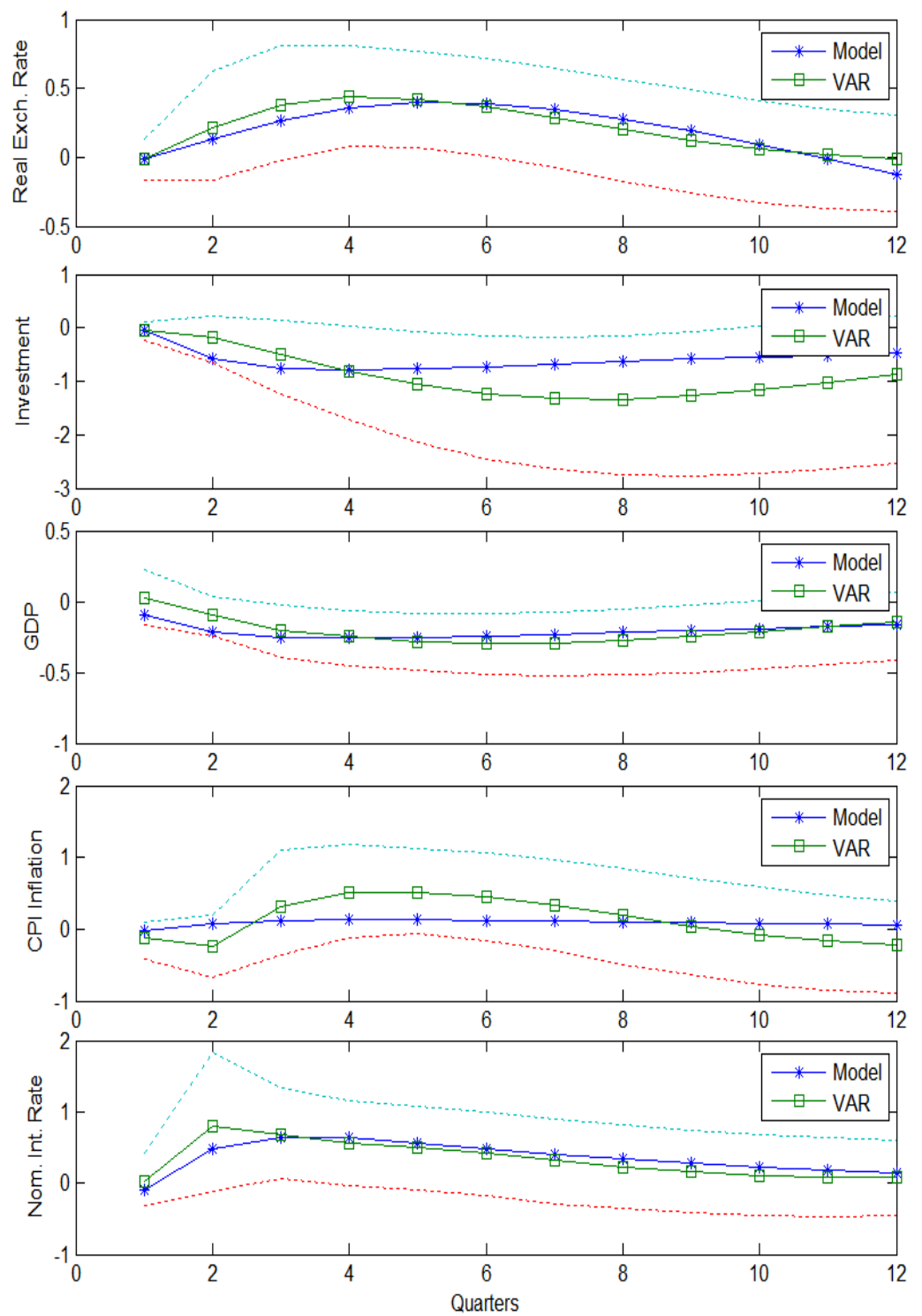

Figure 3: Model and VAR-based responses to an orthogonalized one-standard-deviation positive shock to the U.S. Treasury bill rate 

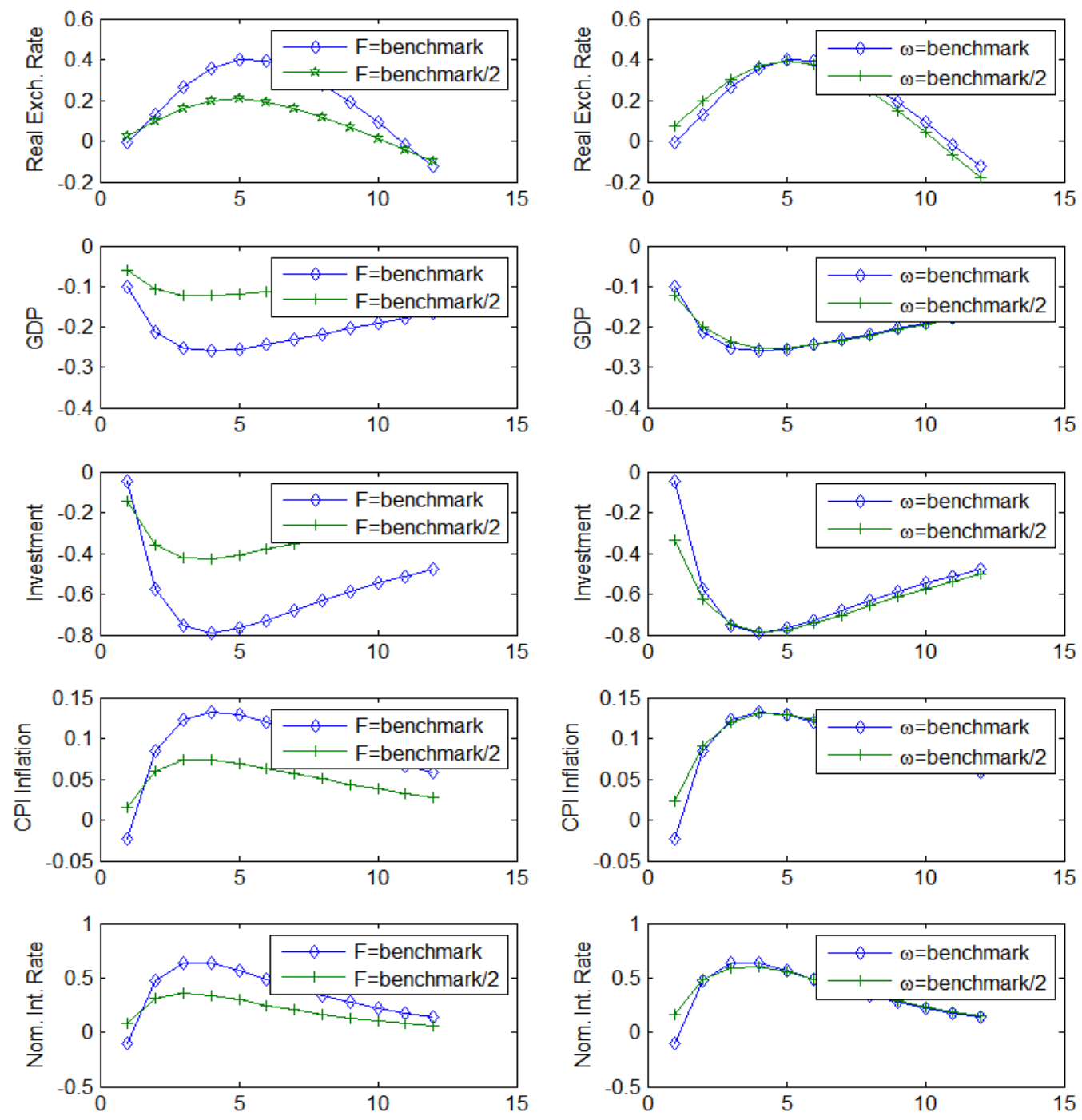

Figure 4: Model-based counterfactual impulse responses 